\title{
Social Sciences
}

2021; 10(5): 237-240

http://www.sciencepublishinggroup.com/j/ss

doi: $10.11648 /$ j.ss.20211005.15

ISSN: 2326-9863 (Print); ISSN: 2326-988X (Online)

\section{Analysis of Female Sexism from the Perspective of English Language}

\author{
Zhang Xinlian \\ College of Foreign Studies, Shandong Technology and Business University, Yantai, China
}

Email address:
zhang_xinlian@163.com

\section{To cite this article:}

Zhang Xinlian. Analysis of Female Sexism from the Perspective of English Language. Social Sciences. Vol. 10, No. 5, 2021 , pp. $237-240$. doi: $10.11648 /$ j.ss.20211005.15

Received: September 16, 2021; Accepted: October 21, 2021; Published: October 29, 2021

\begin{abstract}
Language is an important part of social culture. Language and culture interact with each other and are mutually conditional. Language is a mirror reflecting society. The choice of language reflects the culture and ideology of the language users. Sexism, as a universal social phenomenon, will be reflected in languages with specific social and cultural awareness. Sexism is a prejudice without sufficient factual basis held by members of one gender against members of another gender. It is a social attitude that deviates from objective facts and is a direct manifestation of thought. Belittling and discrimination against women are common in English language. Objectively speaking, the term "sexism" refers to both men and women. The word "sexism" in this paper mainly refers to discrimination against women. Language is not static, but evolves with social history. As a result, the degree of sexism in language varies from period to period. Since the 20th century, thanks to the efforts of feminists, linguistic scholars and the public, sexism in the English language has been greatly weakened, and the neutrality of English has become increasingly evident. The phenomenon of sexism in English language has existed for a long time and has received widespread attention. This paper enumerates representative examples of everyday language phenomena, discusses the sexism in English language, explores the reasons behind it, and deduces the development trend of sexism in English language.
\end{abstract}

Keywords: Language, Culture, Sexism, Feminist Movement

\section{Introduction}

As a social phenomenon, language is not only a part of society and culture, but also a reflection of society and culture. Sociologists have pointed out that there is a link between the structure, vocabulary and usage of a language and the gender roles of the speakers of that language. The choice of language reflects the culture and ideology of the language speakers. English, as a language spoken by most of the world, is largely gender-based. Language can reflect the society, and sexism in language can also reflects the social prejudice. Sexism in English language refer to these languages that belittle, insult or ignore women, which are reflected on all levels of English language. With the awakening of woman's consciousness and the development of the feminist movement, sexist language in English has decreased, but due to the profound influence of its historical and cultural background, sexist language still exists in large numbers in the English language. From the perspective of language, we can have a deeper understanding of sexism in English language and have better insight on woman's status and living conditions.

\section{Sexism in the English Language}

\subsection{The Concept of Sexism in the English Language}

The English-Chinese Dictionary defines "sexism" as "gender bias (especially against women)."[1] Sexism in the English language, especially discrimination against women, is an indisputable fact. Jespersen, a Danish linguist, pointed out in his book Growth and Structure of the English Language that English was the most masculine of all the languages he was familiar with. [2] As a social phenomenon, language is not only a part of society and culture, but also a reflection of society and culture. Therefore, we can say that language is a mirror, which reflects people's attitude towards things. Language itself does not have sexism, but it does not mean that sexism in society has no influence on language. Sociologists point out that there is a certain relationship between the structure, vocabulary and usage of language and 
the gender roles of the language. In the long process of English development, the trend of using male words to refer to both sexes has gradually taken shape. Although people don't intentionally discriminate against women when they use it, it still reflects social prejudice. Sometimes it may cause misunderstanding and produces a derogatory and discriminatory word structure for women, so some people call it "sexist language". (gender language).

Sexism is a term used to refer to a class of preconceived assumptions about the "appropriate" roles, attitudes, and physical characteristics of men and women. Its typical feature is that it is more beneficial to men than to women. People can show sexism through behavior, speech and written language. Since the 1970s, sexism has been strongly criticized by feminists, so avoiding "sexist language" as much as possible has become a prominent feature of language variation. Since the patriarchal society, men have played a major role in social activities and productive labor. Therefore, in the English language, whether in terms of word formation, semantics, or pragmatics, it shows the characteristics of being male-centered, favoring males, and degrading females.

\subsection{Names and Addresses That Reflect Prejudice and Discrimination Against Women}

Addressing terms refer to the name or identity of one party to another in a certain language environment. Addressing term is an indispensable part of the complete semantic system, which has a wide range of applications in social life. It can not only express the speaker's respect, intimacy, contempt and other feelings towards the listener, but also play a role in establishing a specific social relationship between them. At the same time, it can reflect the user's specific level of cultural knowledge, traditional habits, historical background and various cultural factors. In English, all the titles related to men reflect a kind of commendatory color recognized by society. For example, King, Lord, baronet, mister, sir and so on, all these words embody a kind of power. However, the corresponding forms of female titles, such as Queen, Lady, Dame, mistress, Madam, etc., have some extended derogatory connotations in different degrees. For example, King represents a symbol of power in English culture, which can also be extended to an accomplished giant. The English expression of steel king is a steel king; the pejorative use of queen, on the other hand, refers to a prostitute. Lord refers to the "monarch" and "aristocrat" with high status and power, while the corresponding female word "Lady" is no longer used for women of high class. Baronet refers to the "baronet" with prominent status, while Dame refers to ordinary "woman".

Mr, Mrs, and Miss are the most concentrated manifestations of gender discrimination in language in the English pronoun system. No matter how old a man is, or whether he is married or not, he is called Mr., but the woman changes her original Miss. to Mrs. after marriage and loses her surname. For example, Thatcher in Thatcherism, the former British Prime Minister, is her husband's surname. [3] In English, the form of Mr. + surname is often used to address men with higher status or position, such as Mr. Brown. Among them, Mr. does not show the age and marital status of the addressed person. Addressing women is different. Mrs. + husband's surname means married, as Mrs. Brown (Mr. Brown's wife), and Miss+ surname means unmarried woman. In many social situations, this is a problem that embarrasses women. For westerners, marital status is personal privacy. When a woman uses Miss. or Mrs., she publicly announces to others the marital status that they are unwilling to express, which can be said to be a violation of women's rights. The title of male addresses, regardless of whether they are married or unmarried, is collectively referred to as Mr. There are also differences between men and women whose marriages have suffered setbacks. A divorced man is called "bachelor", which means he has an optimistic future. Divorced women are called 'divorcee', which clearly records the unhappy past of women.

Name is a kind of symbol. It is a sign that people can distinguish from each other. It reflects the cultural phenomenon of a society and the embodiment of human ideology. When choosing a name, people often add their own subjective wishes and social attitudes to the name consciously or unconsciously. The traditional social concept requires women to be beautiful, virtuous and graceful, gentle and lovely, which can be reflected in women's names. For example, Susan means "elegance and kindness", while Diana comes from Greek, meaning "moon goddess", which is a symbol of beauty, elegance and nobility. In addition, in English-speaking countries, children generally follow the father's surname, and the family name is passed down from generation to generation. When a woman marries, she takes her husband's surname. As a subordinate to the man, she is said to "follow the cock in marriage and follow the dog in marriage." Therefore, the expression Mrs. Smith (Mrs. Smith's wife) came into being. People always address each other in a certain form of language in communication, and addressing terms have important social functions. It is a recognition of the social identity, status, role and mutual relationship of the person being called. [4]

\subsection{Lexical Sexism: Structure of Words with a Negative Connotation of Discrimination Against Women}

The linguist J. Greenbery proposed a theory of "signs" and "no signs". This "sign theory" provides insight into the phenomenon of sexism in language. [5] Most male nouns are unmarked, while female nouns are often marked, that is, female nouns are often suffixed from male nouns. This word formation itself contains a male-centered meaning and reflects gender discrimination.

In English, there are many female professional nouns derived from male words. For example: poetess, actress, air hostess, editress, waitress, conductress, etc. In English word formation, some nouns with - ar, - or, - er are originally used for both sexes. For example: Minister, Professor, doctor, teacher, etc. Even the term "female" is derived from male, which implies the subordinate status of women in society.

When referring to men and women who share the same characteristics, people often tend to use two words with very different emotional meanings, and the words used to describe women often carry negative connotations. [6] Many word 
structures have no distinction between good and bad. It is people's opinions and social prejudices that make them have this distinction. Some words in English have the connotation of denigrating women or treating them as male appendages. For example, some words do not have the meaning of male symbol in form, so people usually treat them as male words. British and American people habitually think that professor, doctor, lawyer, surgeon, etc. are men. The term "male" is used to refer to both men and women. Even the U.S. Constitution contains this generalization, as in "If a person breaks the law, he will be punished." [7] According to the study, among the 1284 sentences containing the usage of "he" and "she" in the two texts of the ELL corpus, "he" refers to "everyone" in general in 964 sentences, accounting for $75.09 \%$; while "she" refers to everyone in general in only two sentences, accounting for $0.15 \%$ [8]. This shows that the use of the word "male" to refer to both men and women is common, which reflects the discrimination against women.

The meaning of some female words changed from decline to denigration. In the development of English, the meaning of many words has changed from praise to derogation. Words that can be used to represent women in history have gradually become derogatory words, and even have completely different meanings from the original words. For example, governor in Old English refers to the head of a region exercising sovereignty, which still retains this basic meaning. But the original equivalent of governess has become the meaning of "governess", even "mistress".

The distinction between nouns, verbs and adjectives used for both sexes reflects sexism in language. In people's lives, the words used to describe women are usually derogatory or contemptuous, while the words used to describe men are often commendatory or positive.

\section{The Feminist Movement and the Neutralization Trend of English Language}

\subsection{The Feminist Movement and Effects Made by Women's Rights Movements}

The phenomenon of sexism in the English language belongs to both the field of linguistics and sociological research. [9] In the 1960s, American women launched a social movement to fight for women's freedom to enjoy equal rights and opportunities (political, economic, social, legal, etc.) for women. It was called the "Women's Liberation Movement", also known as "the Feminist movement". Feminists are committed to reforming sexist things, especially language. The most obvious is to replace male-centric words with neutral words. [10]

Language is a tool for humans to communicate with each other, and it does not produce any prejudice against anyone. In recent decades, with the awakening of women's consciousness and the development of feminist movement, sexism in English has attracted more and more attention. Feminists and many linguists are working hard to eliminate sexist language. The feminist movement has also brought about great changes in the English language on the basis of social development. These efforts and movements have enriched and improved the English language.

Language is a symbol of social convention, which has the characteristics of variability and profundity. Through the analysis and study of vocabulary, we can see the changes and vicissitudes of society. As far as English is concerned, we can see many linguistic phenomena that discriminate against women. However, with the vigorous development of the women's liberation movement in the world and the increasing status of women, the gender phenomenon of language is becoming less and less. [11]

\subsection{Noun with Suffix "Woman"}

Nowadays, the phenomenon of sexism in English shows a declining trend. People use multilingual strategies such as creating new words and avoiding male words to weaken sexism. [12] Feminist activists have found that many English vocabulary, especially those related to occupations, actually exclude the role and identity of women. This is unacceptable for them. Feminist activists are extremely dissatisfied with masculine nouns such as chairman, spokesman, policeman and statesman. They argue that such nouns have a strong prejudice against women. "It seems only men are suitable for these jobs?" they further retort, "What right do men have to treat this type of occupation as their patent? Don't we women have the right to engage in this kind of occupation? Men can do it, so can we!" Feminists have proposed a way to show that women are equal to men in the workplace: According to the principle of word formation, the suffix "WOMAN" is added to the root of a word to form a negative noun, which greatly enriches English vocabulary. If men can become statesman (statesman), then women can also become stateswoman (stateswoman), similarly:

1. Chairman vs Chairwoman,

2. Spokesman vs Spokeswoman,

3. Policeman vs policewoman,

4. Congressman vs congresswoman,

Feminists believe that some of the language contains "sexist meaning", which is called "sexist language". In other words, the meaning of a word is limited to one gender, but it represents the meaning of two genders. For example, the meaning of the word "chairman" refers to "the person chairing the meeting". This "person" may be a woman or a man, so "chairman" is called a word with a discriminatory meaning towards women. Therefore, some people avoid the use of chairman, and use a non-sexist word-chairperson. They try to change or eliminate sexist words, and avoiding the use of man is a prominent feature.

\subsection{Popularizing New Words}

The influence of the feminist movement on language is also reflected in marriage. Sociolinguist Bollinger argues that sexism in English is due to the fact that women have always 
been seen as commodities and property in Western society. [13] In modern Western society, being married and not being married is a very sensitive issue for women. Of course, in social life, for example, in employment, married and unmarried also have distinct opportunities. When men use the word Mr. (Sir), it doesn't reveal anything about their marital status, so feminists coined the word Ms. to correspond with Mr. And to defy the custom of identifying a woman by her marital status, instead of using Mrs. or Miss. It not only cleverly avoided the difference between married and unmarried, but also made people understand that they were called women, and achieved equal status with Mr., enabling women to compete for the same status as men in marital status. The term has now been included in the "English-Chinese Dictionary", "Oxford Modern Advanced English-Chinese Dictionary" and other major dictionaries.

\section{Conclusion}

The phenomenon of sexism is linguistically formed, but socially and culturally rooted. The gender differences and sexism reflected in language are not a natural part of language, but a natural reflection of the values of a particular society and national mindset. From a psychological perspective, sexism is rooted in gender bias. Palmer, a British linguist, once said, "Language is the most irresistible social phenomenon that exerts power on people in the most subtle way." [14] As an important part of culture, language is also an important carrier of culture. Culture depends on language to preserve, spread and inherit, so language reflects a kind of culture. As an objective linguistic phenomenon, sexism in English language also reflects certain historical background, culture and social traditional concepts. Therefore, to eliminate the phenomenon of gender discrimination in language, we should not only focus on the form of language, but also eradicate the concept of gender discrimination in society and further improve the social status of women. With the development of human civilization, we believe that sexism in language will attract more attention and eventually disappear with the elimination of sexism in traditional culture. [15] With the awakening of women's consciousness and the development of feminist movement, the number of sexist language in English has decreased. However, due to the profound influence of its historical and cultural background, sexist words still exist in English. In order to eliminate gender discrimination in language, we must first strive to eradicate the concept of gender discrimination and the social phenomenon of inequality between men and women. The approach to change in English and Chinese is different, but the direction is the same, that is, to remove or fade out the gender discrimination imprinted on the language by social culture.

\section{References}

[1] Lu Gusun. English-Chinese Dictionary [M]. Shanghai: Translation and Publishing.

[2] Shanghai: Translation and Publishing House, 2007: 1706.

[3] Jespersen, Otto. Growth and Structure of the English Language [M]. Bristol: Western Printing Services Ltd, 1938.

[4] Xiao Yan, Wang Guiping. Gender discrimination in English and Chinese languages [J]. Journal of Tongling College, 2008 (5): 94-96.

[5] Hongmei. A comparative study of sexism in English and Chinese language and its causes [J]. Journal of Mudanjiang Education College, 2008 (6): 41-42.

[6] Gu Jiazu. Language and Culture [M]. Shanghai: Shanghai Foreign Language Education Press, 2002: 57.

[7] Zhang Yiman. An analysis of gender discrimination in English vocabulary [J]. Overseas English, 2018 (11): 227.

[8] Hou Zuoxun. The current situation and cultural connotation of sexism in English language [J]. Modern Agricultural Research, 2019 (3): 103.

[9] Qu Qiao. Current situation and cultural connotation of English language and gender discrimination [J]. Journal of Shandong Agricultural Engineering College, 2018 (1): 146.

[10] Li Qiang. Applied Sociology [M]. Beijing: China Renmin University Press, 2004: 484.

[11] Liu Mo. Women's Liberation Movement and English Vocabulary [J]. Journal of Sichuan Foreign Studies University, 1995.

[12] Dong Xiaobo. Sex Discrimination and Feminist Movement in English [J]. Nanjing Normal University Journal, 2002.

[13] Li Jing. Research on the development trend of gender language differences in English [J]. Journal of Zhejiang communications vocational and technical college, 2012 (1): 79 - 82.

[14] Lin Fang. Analysis of gender discrimination in English language and Its Countermeasures [J]. Journal of Tianjin Sino German Vocational and technical college, 2015 (6): 70.

[15] Palmer. Introduction to Linguistics [M]. Beijing: Education Press, 1997: 108.

[16] Yang Yongzhong. Gender discourse patterns [J]. Language Teaching and Research, 2002, (2). 